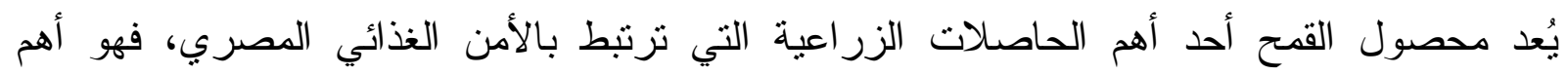

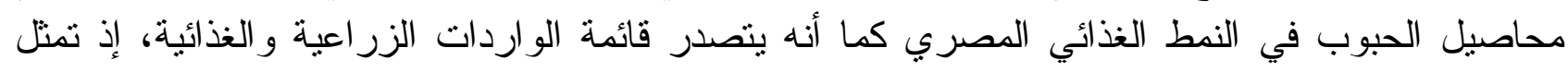

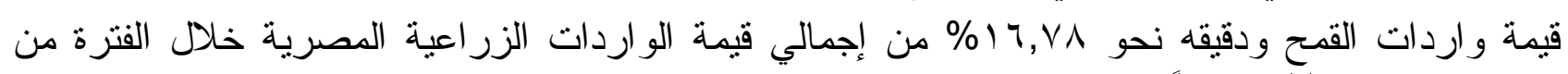

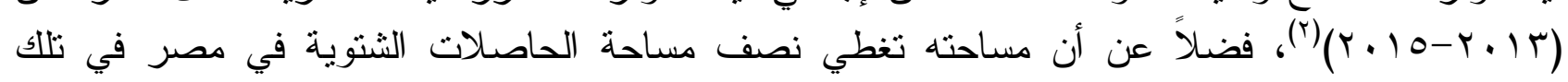

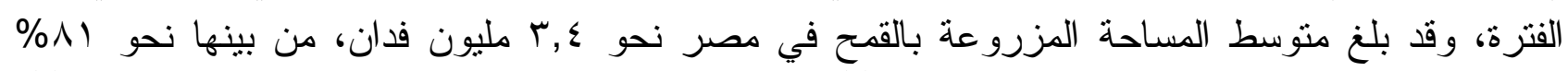

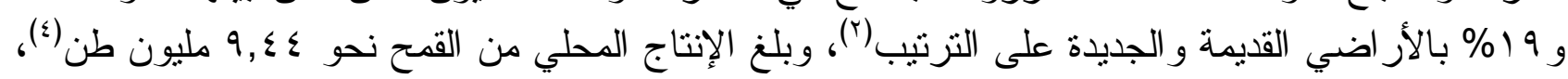

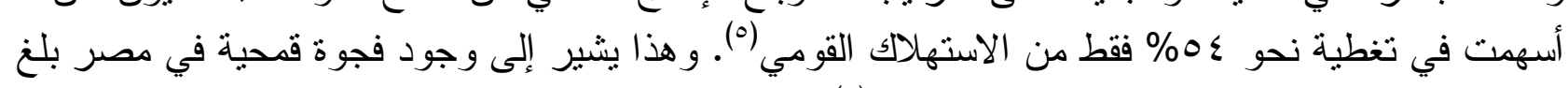

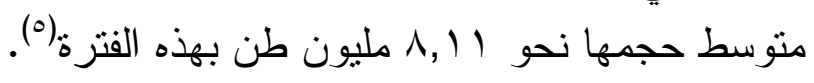

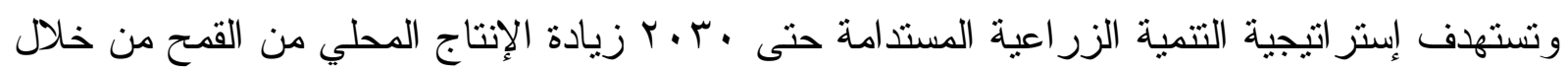

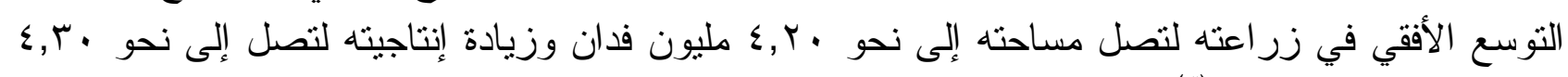

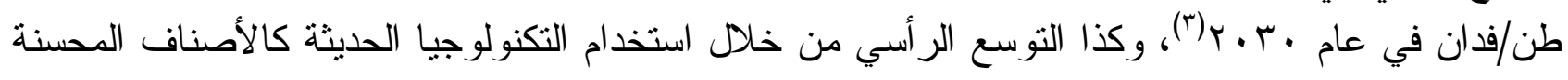

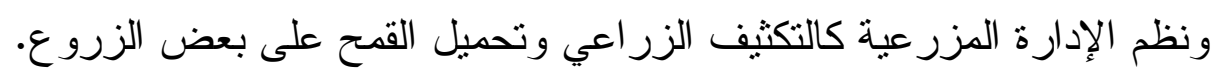

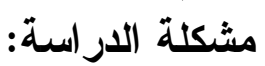

تتمثل مشكلة البحث في قصور الإنتاج المحلي من محصول القمح عن تلبية الاحتياجات المحلية

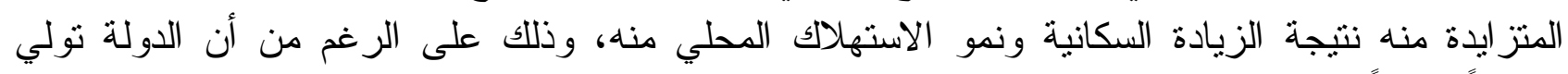

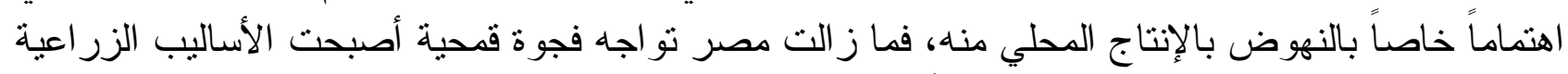

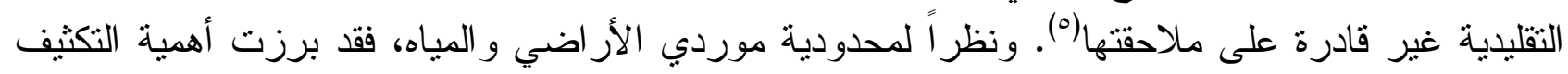

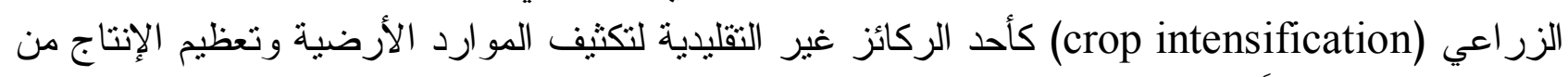

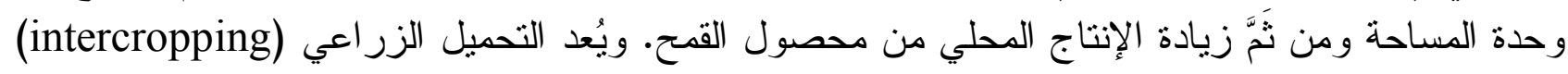

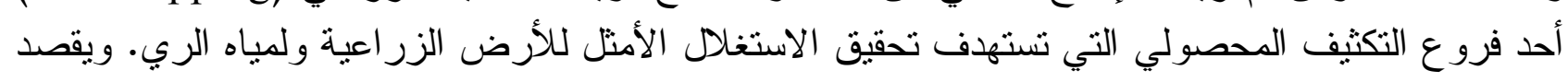

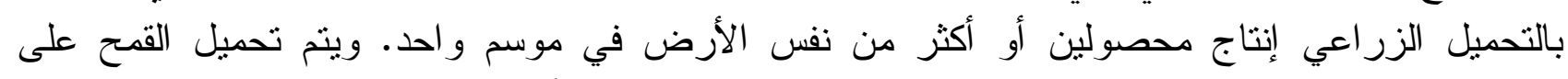

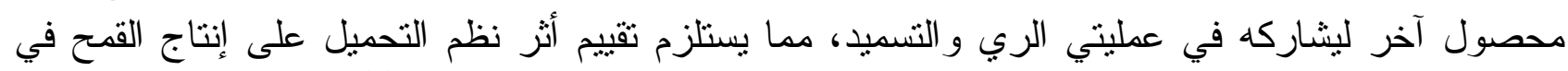

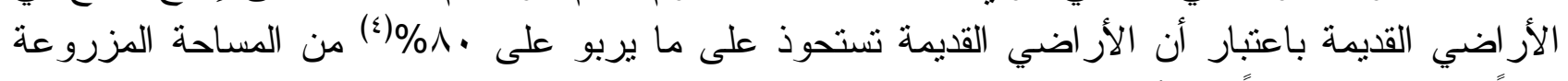

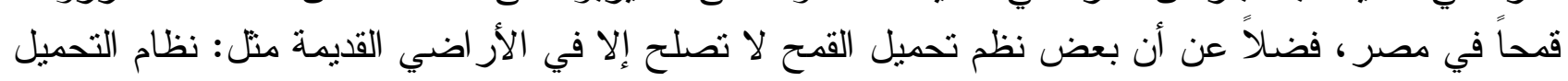
المناوب للقمح على القطن. هدف الاراسة:

يستهدف البحث بصفةٍ أساسيةٍ دراسة أثر استخدام نظم تحميل القمح في الأراضي القديمة على الكفاءة

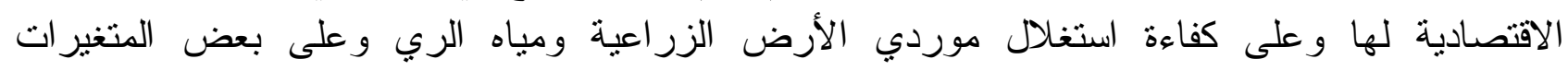

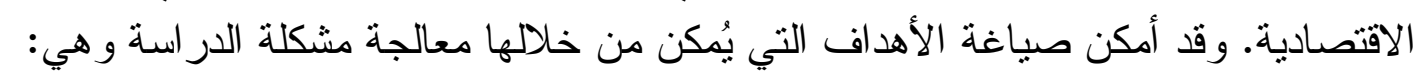

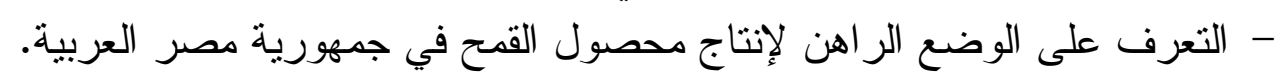

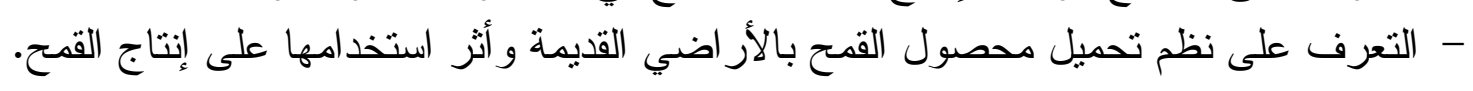


المردود الاقتصادي لنظم تحميل محصول القمح بالأر اضي القديمة على استخذام موردي الأرض و المباه .

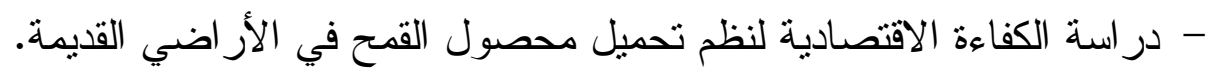

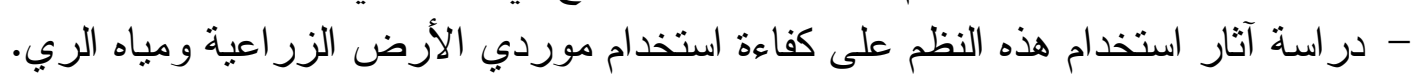

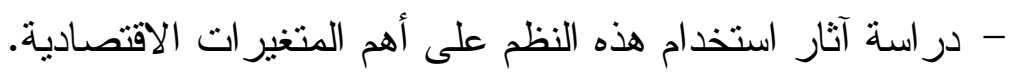
الطريقة البحثية ومصادر البياتات:

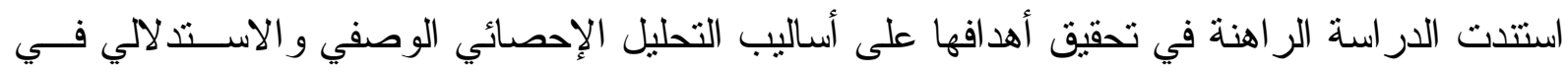

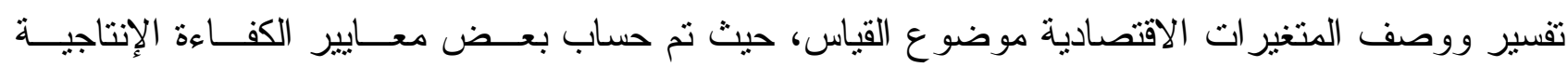

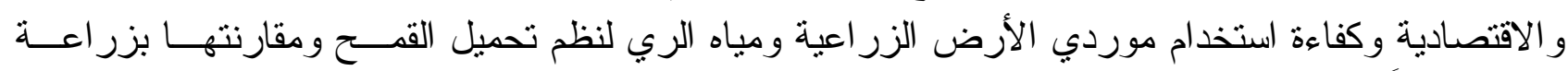

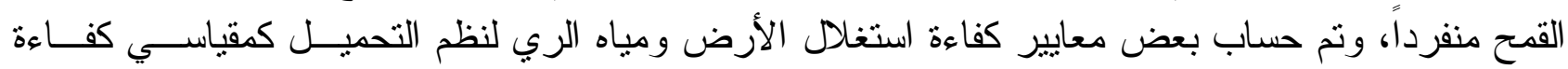

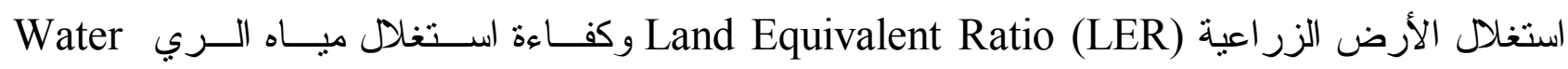
Equivalent Ratio (WER)

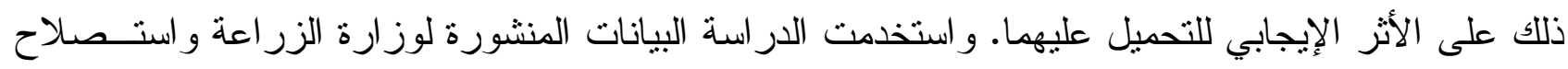

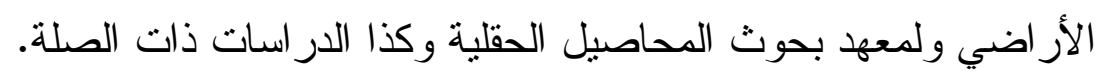

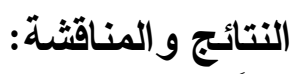

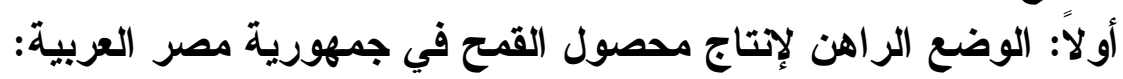

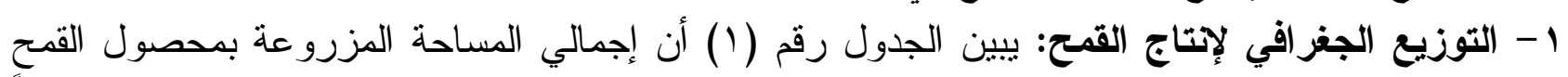

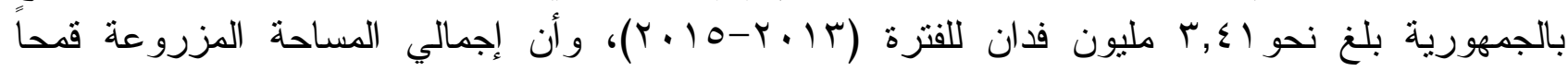

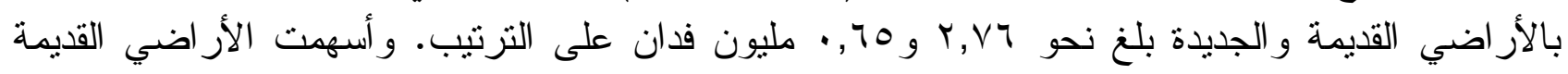

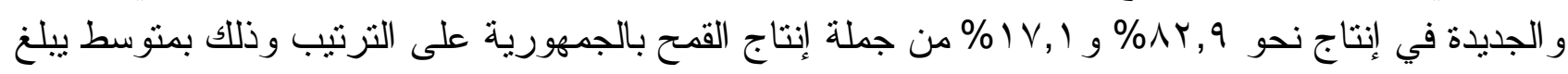

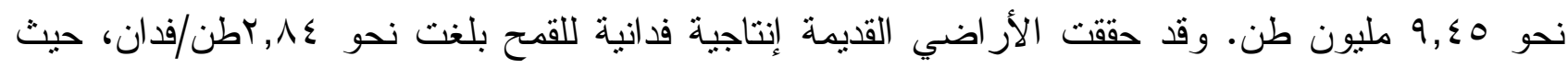

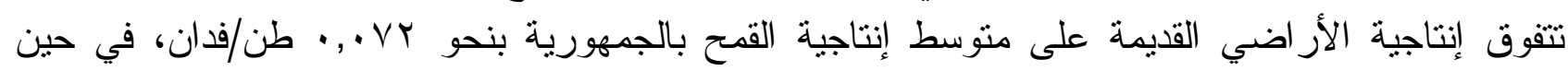

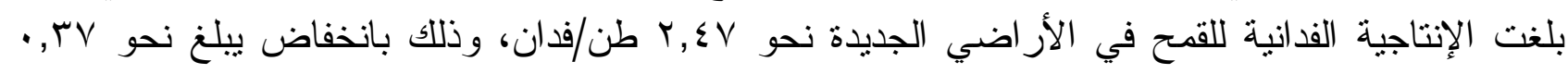

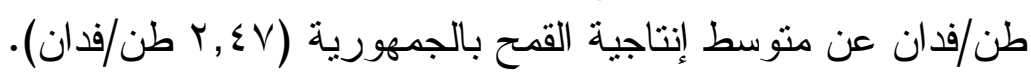

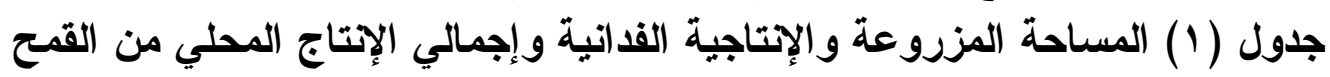

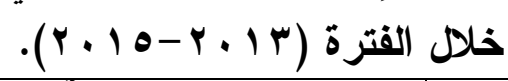

\begin{tabular}{|c|c|c|c|c|c|c|}
\hline \multicolumn{2}{|l|}{ 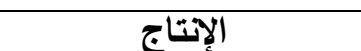 } & \multicolumn{2}{|l|}{ الإتتاجية } & \multicolumn{2}{|c|}{ المساحة } & \\
\hline \% من الجمهورية & 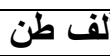 & الفرق عن متوسط الجمهورية (طن) & |طن |قدان & \% من الجمهورية & |ألف قُان| & \\
\hline$\lambda Y, q$ & VAT. & $\overline{\theta, \cdot V Y}$ & $r, \wedge \varepsilon \cdot$ & $\Lambda \cdot, \Lambda$ & TVOV & ر راضى القديمة \\
\hline $\mid V, I$ & 1719 & $(\cdot, r V \cdot)$ & $r, \Sigma V_{\text {. }}$ & $19, r$ & 707 & 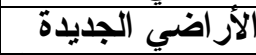 \\
\hline $1 \cdots$ & $9 \leqslant \varepsilon 9$ & $\cdot, \cdot$, & T,VTA & $1 \cdots, \cdot$ & $T \leqslant 1 T$ & |لجمهورية \\
\hline
\end{tabular}
الأرقام بين القوسين تعبر عن قيم سالبة.

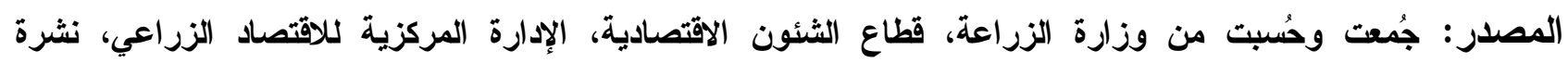
الإحصاءات الزراعية.

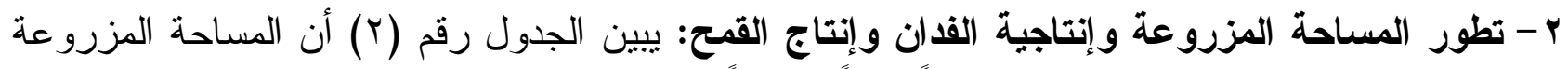

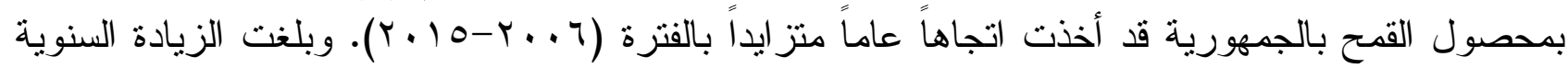

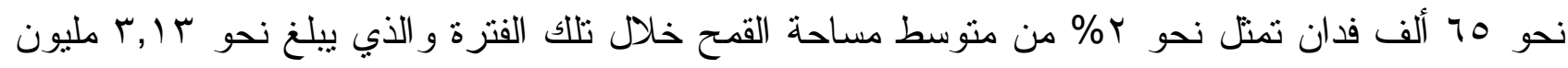

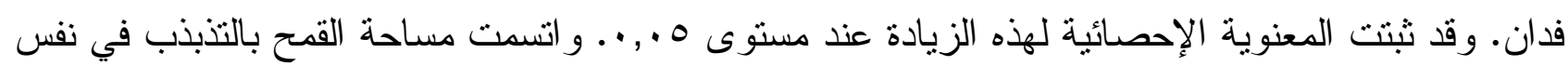

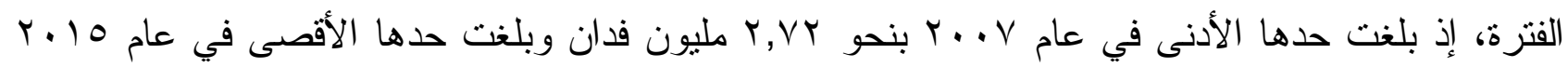

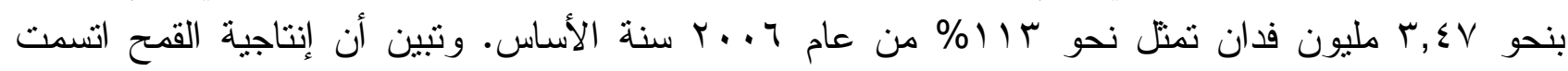


بالتذبذب حول متوسطها البالغ حو الي Y,V) طن/فدان خلال نفس الفترة، إذ بلغت الإنتاجية حدها الأدنى عام

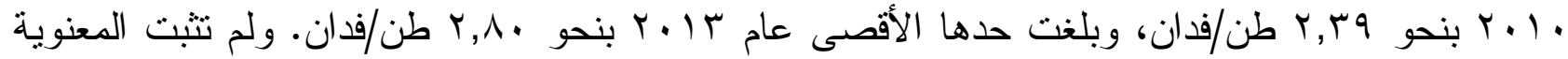
الإحصائية لزيادة إنتاجية فدان القمح للجمهورية في تلك الفترة. ويشير الجدول إلى أن الإنتاج الكلي من القمح

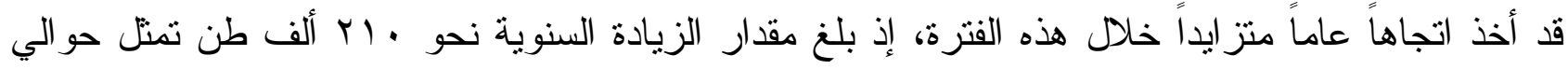

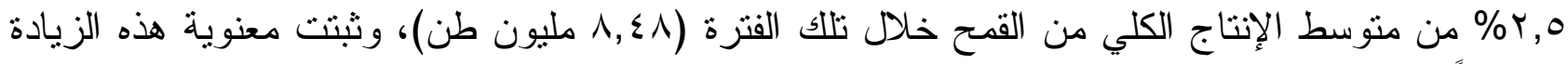
إحصائياً عند مستوى 0 •, •.

جدول (Y) تطور المساحة المزروعة والإتتاجية الفدانية وإجمالي الإتتاج المحلي من القمح في الفترة $\cdot(r \cdot 10-r \cdot 7)$

\begin{tabular}{|c|c|c|c|c|c|}
\hline التغيز السنوي (1) & المتوسط & $\begin{array}{c}\text { P- } \\
\text { value }\end{array}$ & 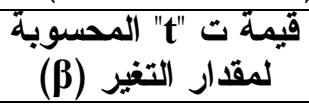 & مقدار التغير & ت ت تغيرات \\
\hline$r, \cdot \Lambda$ & 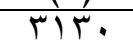 & $\cdot, \cdots r$ & $* \varepsilon, \varepsilon 9$ & $70, Y 11$ & المساحة المزروعة (ألف فُدان) \\
\hline- & Y,V & $\cdot, \leqslant \vee 7$ & $\cdot, \mathrm{VO}$ & $\cdot, \cdot$, & تتاجية (طن/فُان) \\
\hline T, हV & 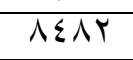 & $\cdot, \cdots 9 V$ & *r, rV & $r \cdot 9, \wedge \leqslant r$ & تتاج المحلي (ألف طن) \\
\hline
\end{tabular}

المصدر: جُمت وحُسبت من وزارة الزراعة، قطاع الشئون الاقتصادية، الإدارة المركزية للاقتصاد الزراعي، نشرة

\section{الإحصاءات الزراعية.}

ثانياً: نظم تحميل محصول القمح بالأراضي القديمة وأثر استخدامها على إنتاج القمح: تتمل نظم التحميل المختلفة لمحصول القمح أربعة نظم هي: التحميل على الطماطم الثتنوية، التحميل على بنجر السكر ، التحميل المناوب على القطن، و التحميل على قصب السكر الخريفي.

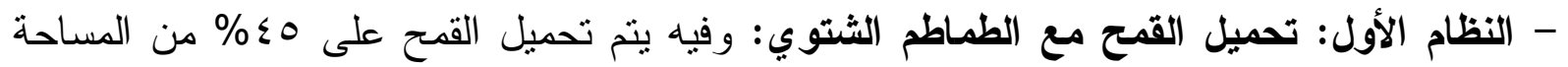
الكلية للطماطم الثتوية، وتتم زر اعة الطماطم في نهاية شهر سبتمبر على مصاطب، وبعد عقد ثمار ها تتم زر اعة القمح محملاً في النصف الأول من شهر نوفمبر وبمعدل سطرين على جانبي المصطبة، وبذلك يتم توفير التدفئة اللازمة للطماطم ويضمن حمايتها من الصقيع ومد موسم نموها لنهاية شهر مارس و استمر ار ها

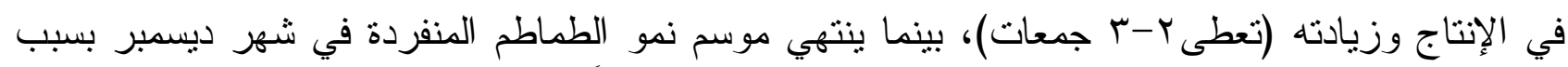
الصقيع، وهو يوفر مياه الري و الأسمدة الكيماوية المستخدمة، فضلاً عن أن الامتداد العميق لجذور الطماطم

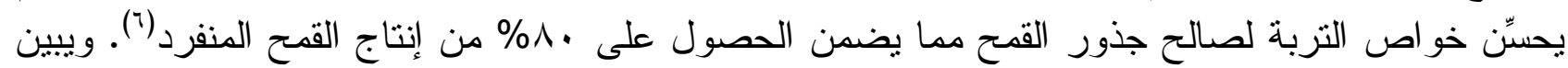

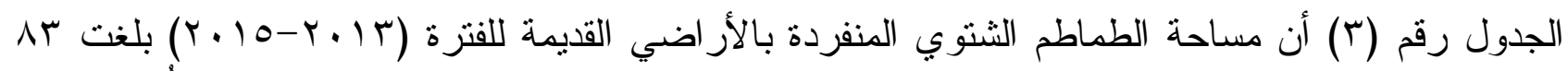

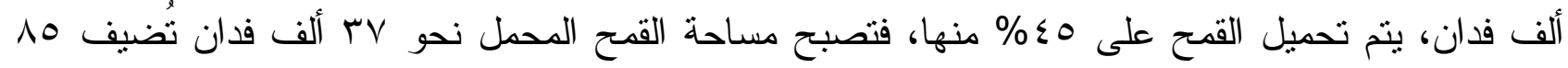
ألف طن من الحبوب إلى إنتاج القمح المنفرد بالأراضي القديمة، ليصبح إجمالي إنتاج القمح (المنفرد

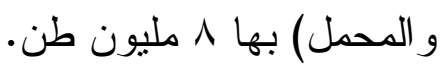
- النظام الثاني: تحميل القمح على بنجر السكر: وفيه تتم زر اعة البنجر في الميعاد المتفق عليه مع المصنع (في شهري سبتمبر و أكتوبر) على جانبي المصطبة، ثم تتم زر اعة سطرين من القمح على ظهر

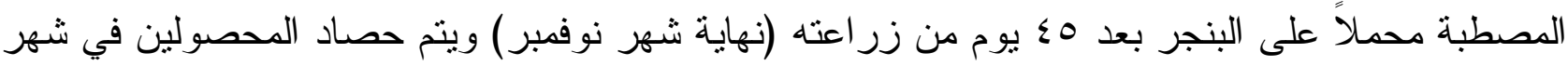
إبريل. ويستقيد محصول القمح من مياه الري المضافة للبنجر فتوفر مياه الري و الأسمدة الكيماوية المستخدمة

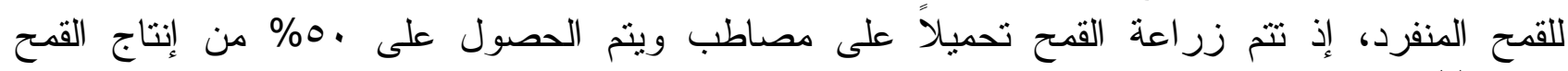

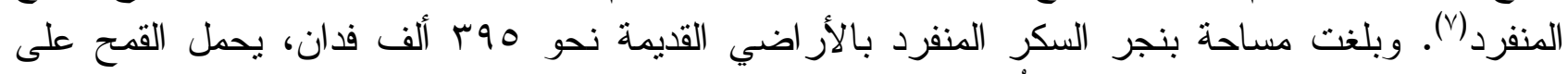

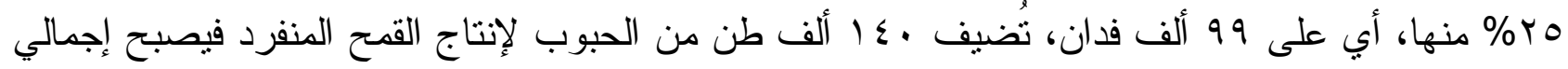
إنتاج القمح بالأر اضي القديمة $\wedge$ مليون طن (جدولبr). 


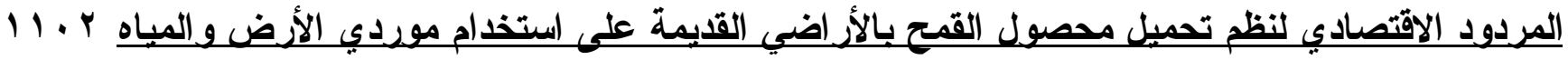

جدول (r) أثر استخدام نظم تحميل محصول القمح بالأر اضي القديمة على إنتاج القمح.

\begin{tabular}{|c|c|c|c|c|c|c|c|c|c|c|}
\hline (لقى القصب المحل) & قُصب الذريفي & على القطمل & المنفرد & على البحمل & النجنر & المحمل مع القمح & $\mid$ & المنفرد & \multicolumn{2}{|c|}{ البيان } \\
\hline$\sum \lambda$ & YAA & $T \leqslant 1$ & YTA & 99 & 190 & TV & N & TVOV & عة (ألف فدان) & المساحة المزرو \\
\hline $1, V$ & . & $T, 07$ & . & $1, \varepsilon Y$ & • & $T, Y V$ & . & $Y, \wedge \varepsilon$ & 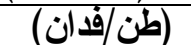 & | \\
\hline 7,71 & . & $1 \cdot, \cdot r$ & . & $0,0 \mathrm{~V}$ & - & $\lambda, 91$ & - & $11,1 \leqslant$ & (حمل/فُدان) & كم \\
\hline NY & - & 717 & - & $1 \leqslant$. & - & 10 & . & VAr. & (ألف طن) & \\
\hline TYV & . & Tई। & . & $0 \leqslant 9$ & • & TrT & - & $r \cdot V) \varepsilon$ & (ألف حمل) & \\
\hline
\end{tabular}

(Ouda and Zohry, 2017) -

المصدر: جُمعت وحُببت من بيانات: - (Ouda and Zohry, 2016)

- وزارة الزراعة، قطاع الثئون الاقتصادية، الإدارة المركزية للاقتصاد الزراعي، نشرة الإحصاعات الزراعية، أعداد متفرقة.

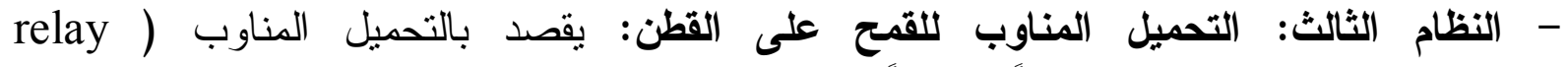

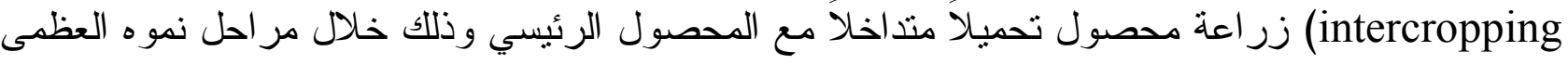

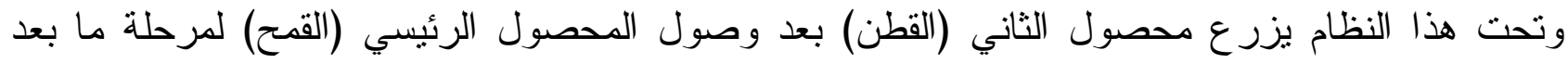
التزهير وقبل النضج النهائي. وفيه تبدأ زر اعة القمح في شهر نوفمبر على مصاطب في سطور على ظهر

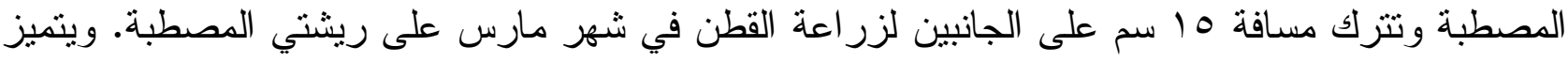
هذا النظام بالحصول على •^- • 9\% من إنتاج القمح المنفرد، كما أنه يوفر ريتين للقطن (هما رية الزر اعة ورية المحاياة للقطن حيث أنها الرية الأخيرة للقهح "رية فطام القهح")، وهو يوفر الأسمدة الكيماوية للمحصولين، كما أن زر اعة القطن في الميعاد الأمثل (شهر مارس) تحميلاً مع القمح يضمن حماية البادرات من التقلبات الجوية، إذ يقوم القهح بتدفئة القطن وزيادة نسبة الإنبات وتجنب الإصـابة بديدان اللوز (بسبب إنبان

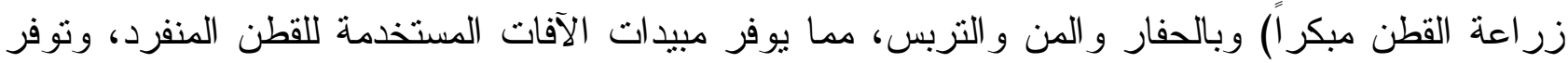

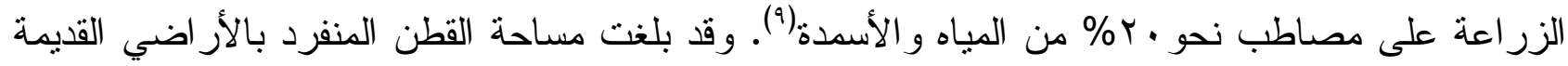

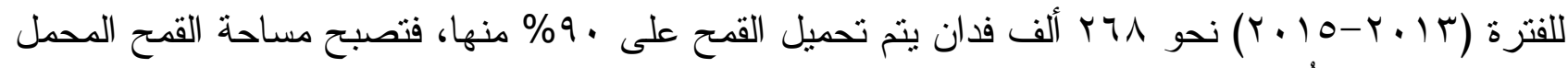

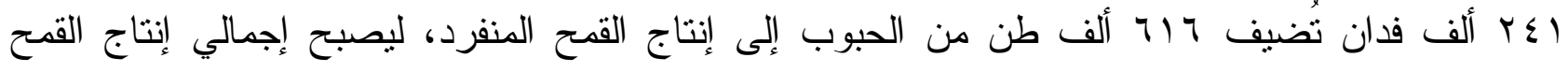

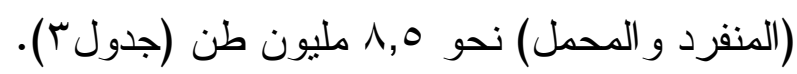

- النظام الرابع: تحميل القمح على قصب السكر الخريفي: يمكث قصب السكر الخريفي في التربة

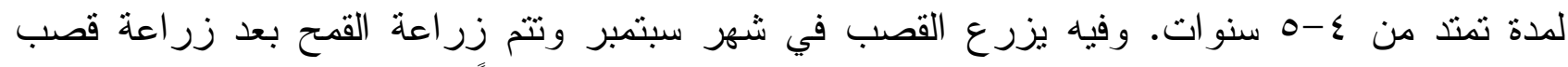

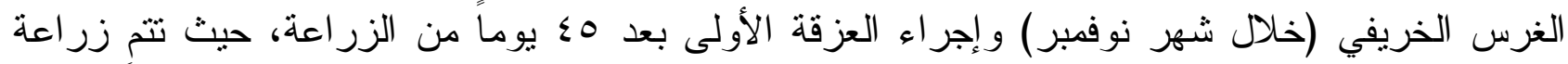

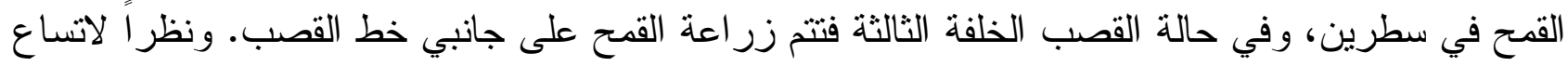

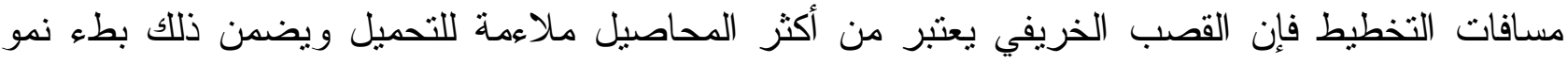
بر اعم القصب خلال شهري سبتمبر و أكتوبر لتمتد هذه الفترة إلى ب-ع شهور • و وعند نضج القمح يتم حصاده

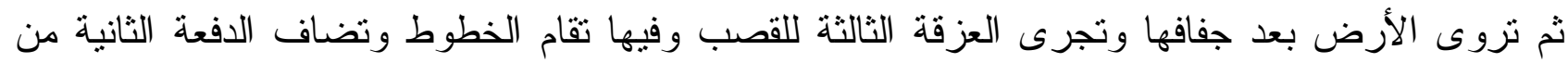

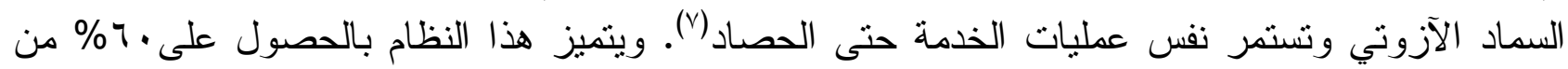
إنتاج القمح المنفرد، كما أنه يوفر مياه الري المستخدمة للقهح المنفرد، إذ يستقيد القمح من مياه الري المضافة

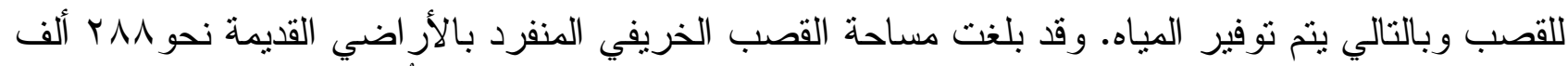

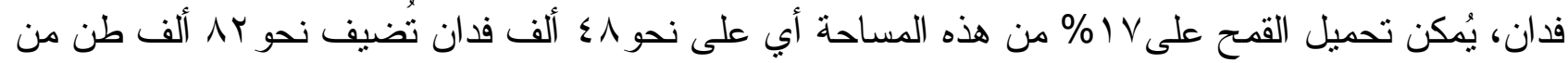
الحبوب لإنتاج القمح المنفرد، ليصبح إجمالي إنتاج القمح (المنفرد و المحمل) بالأر اضي القديمة نحوى مليون 


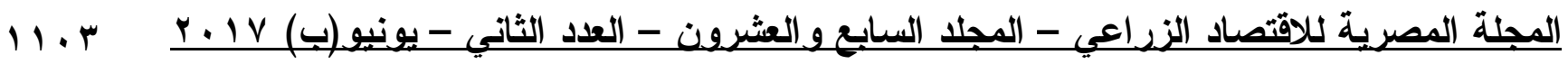

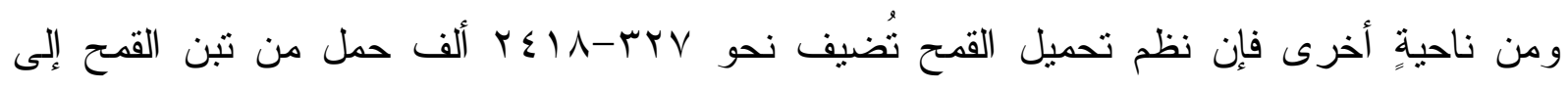

المو ارد العلفية الجافة اللازمة لتغذية الحيو انات فئات

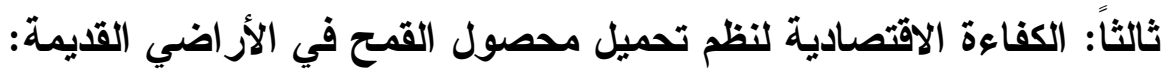

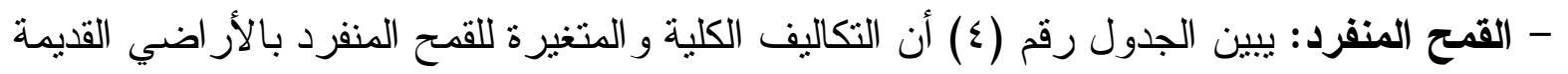

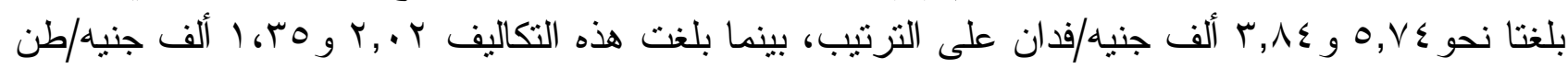

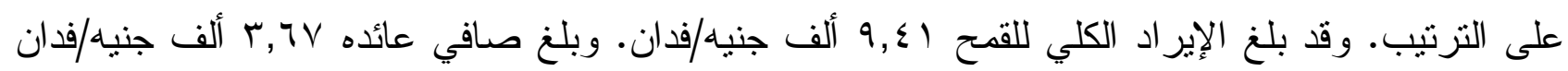

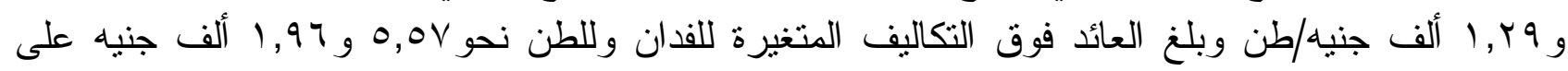

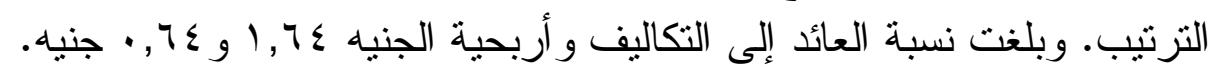

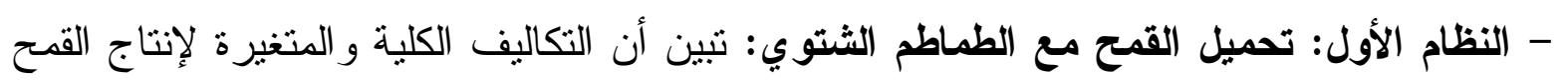

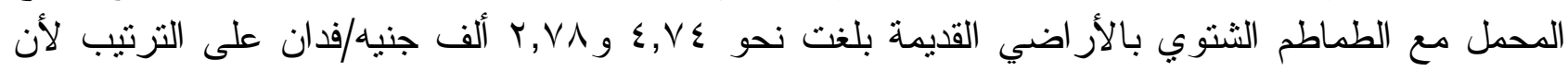

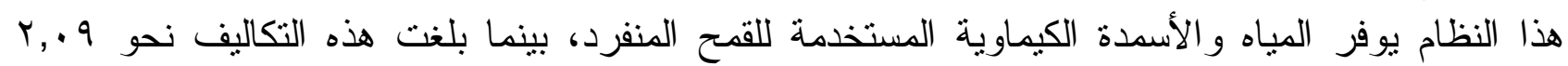

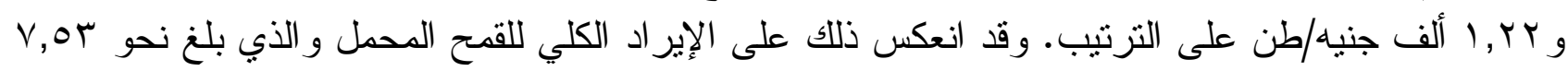

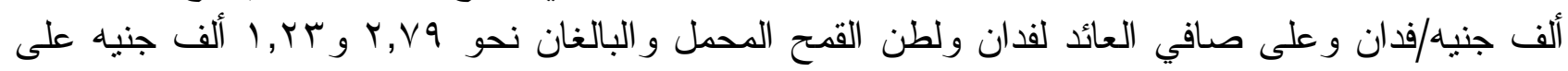

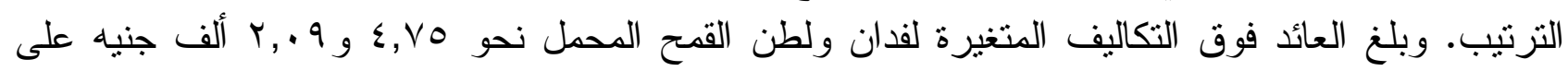

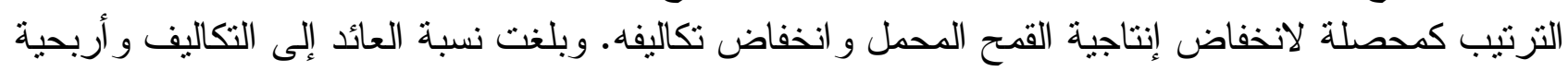

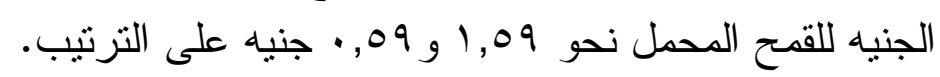

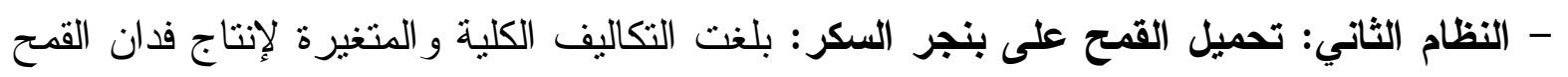

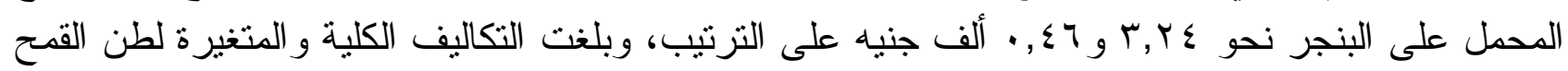

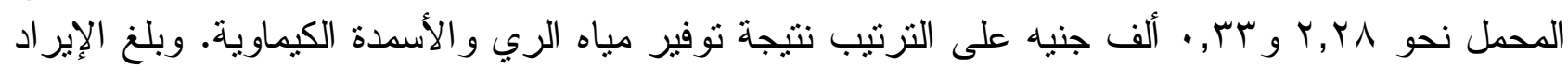

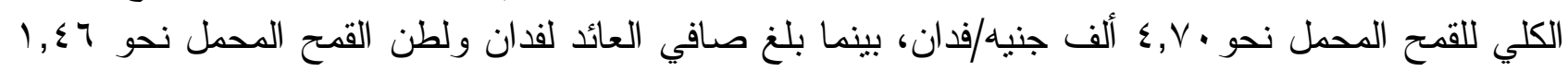

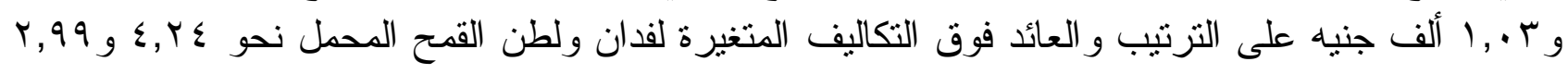

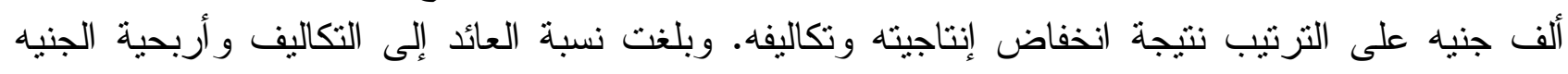

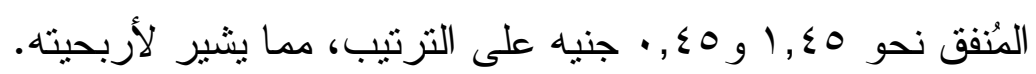

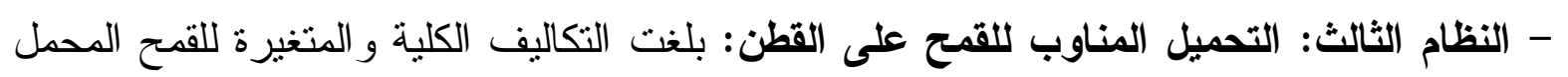

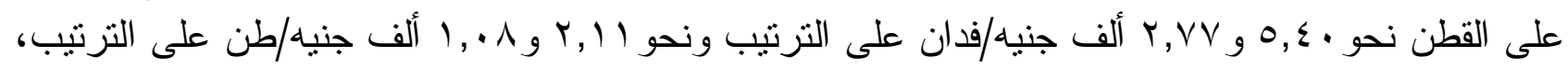

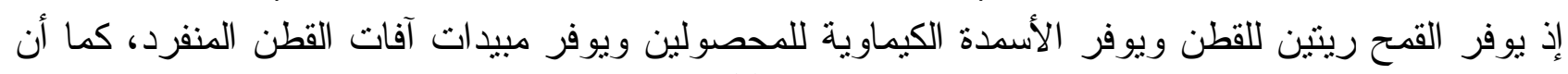

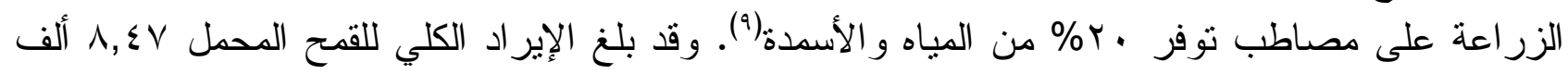

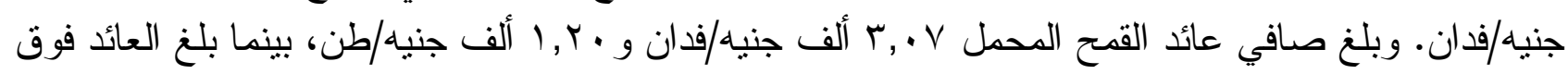

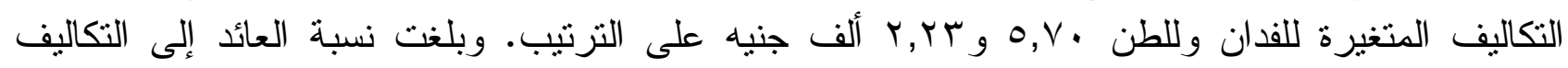

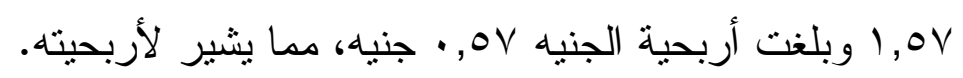

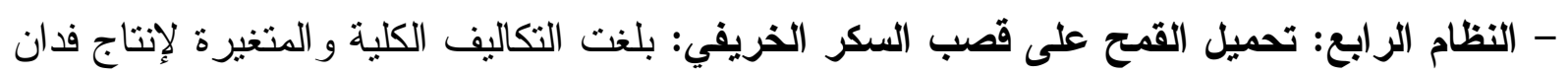

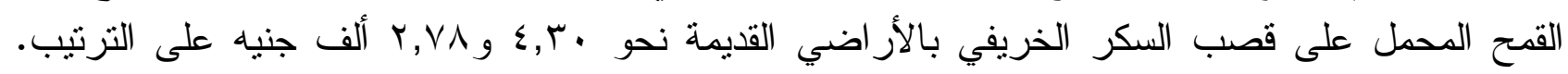

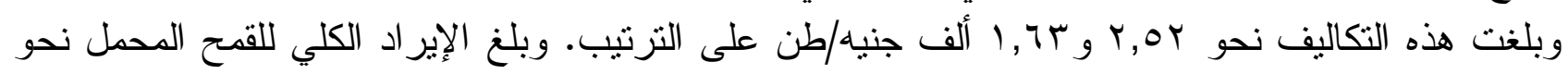

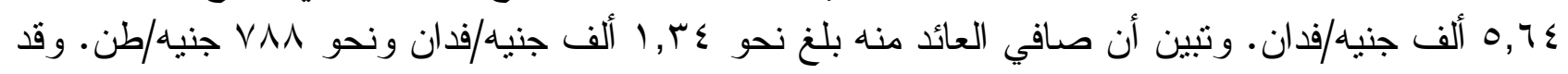

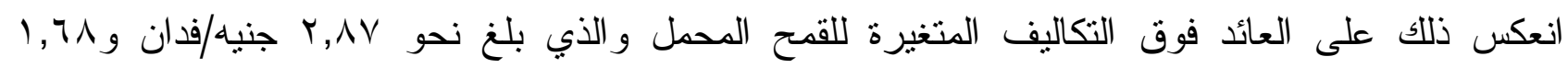

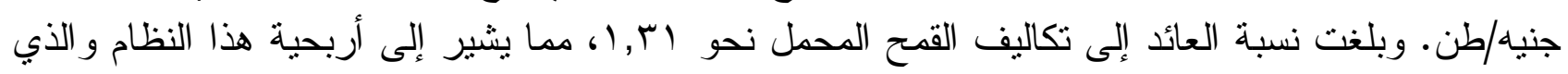




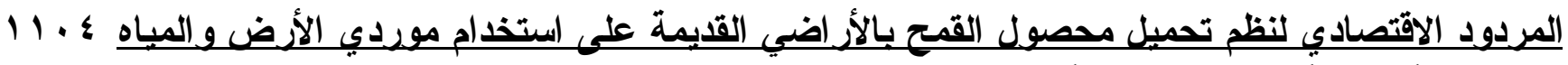

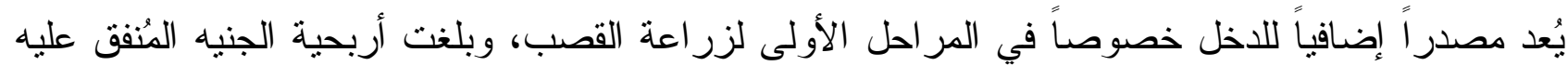

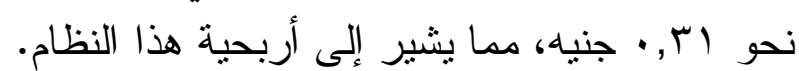

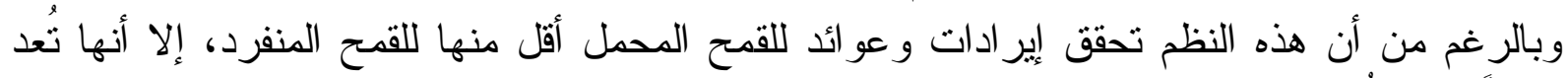

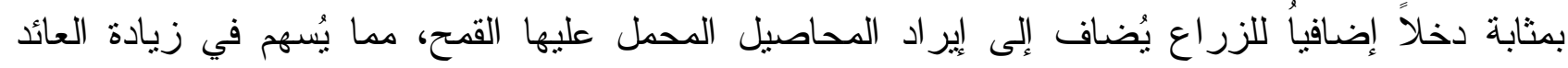

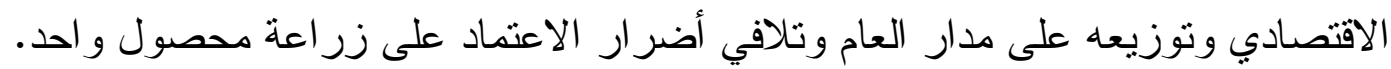

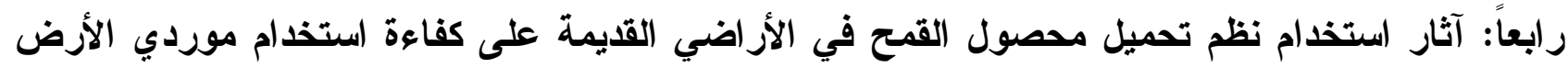

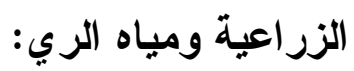
يوضح الجدول رقم (ع) أن نظم تحميل القمح بالأر اضي القديمة تُهم في تحقيق الكفاءة الإنتاجية

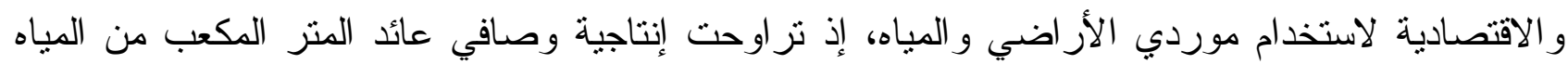

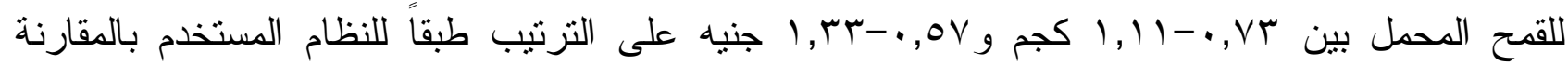

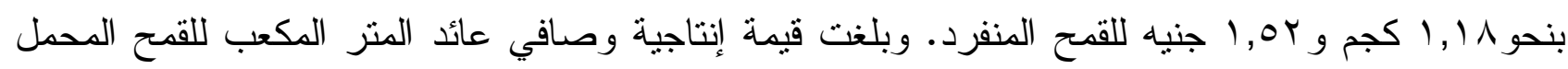

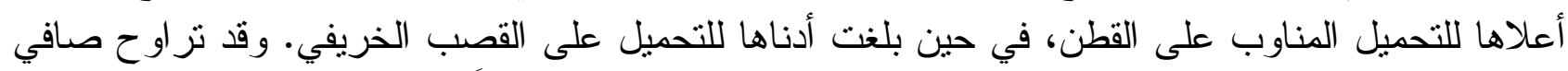

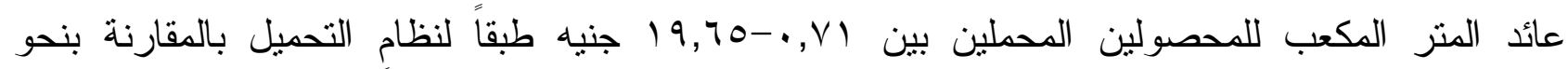

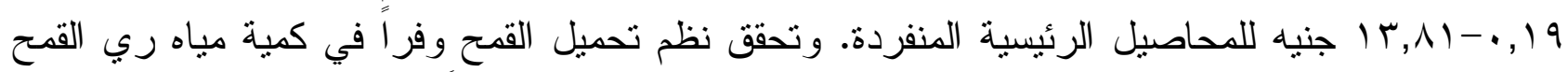

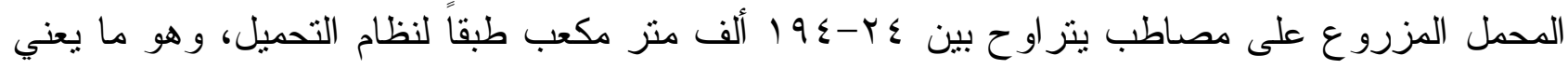

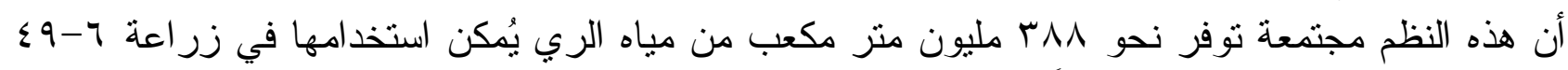
ألف فدان من الأر اضي الجديدة طبقاً لنظام التحميل.

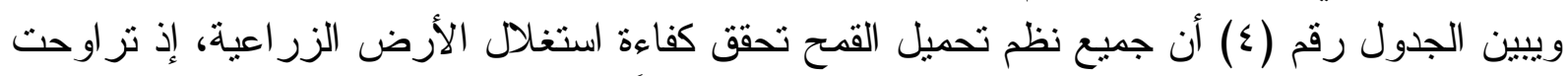

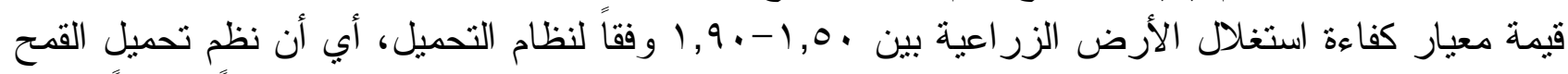

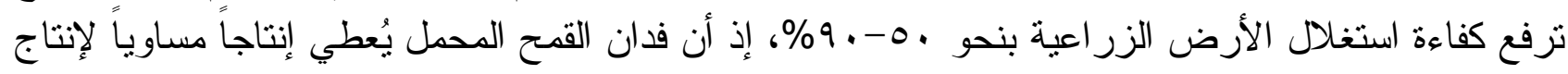

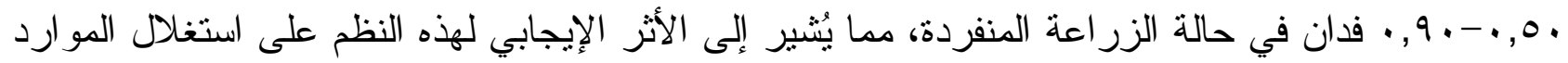

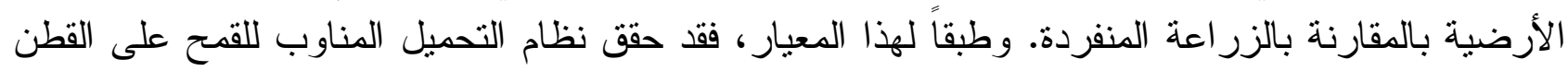

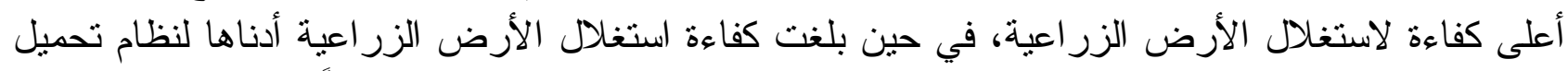

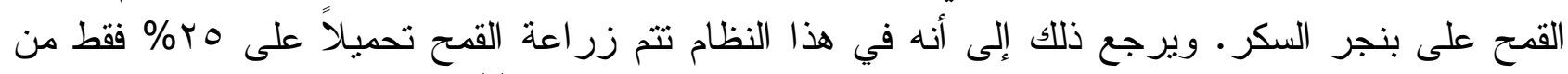

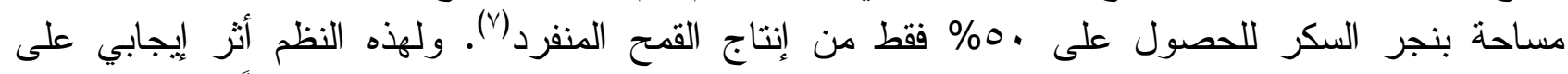

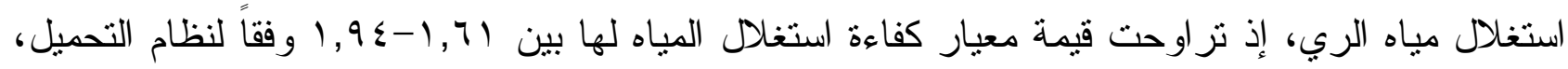

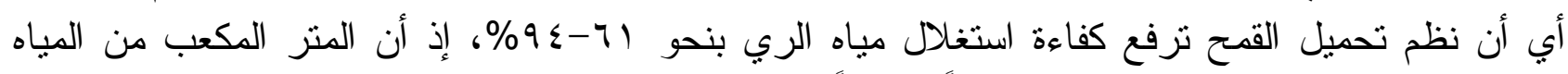

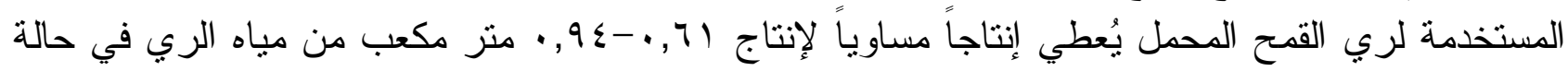

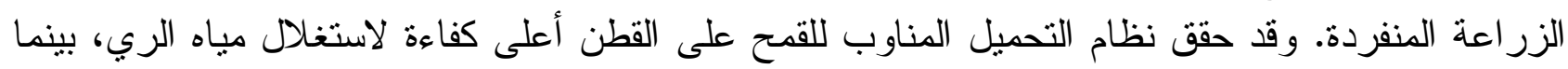

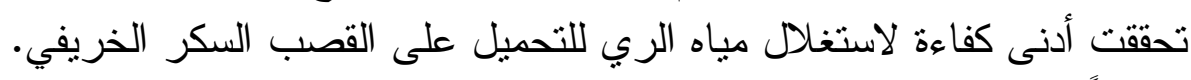

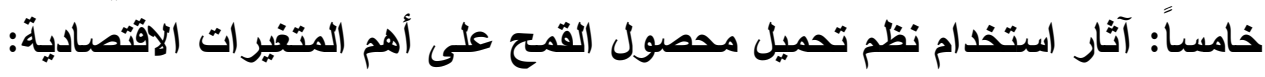

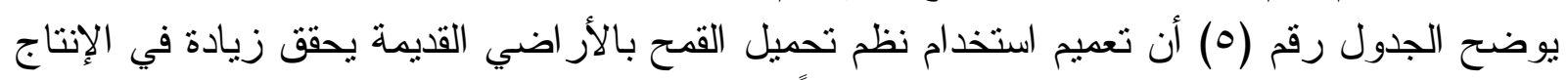

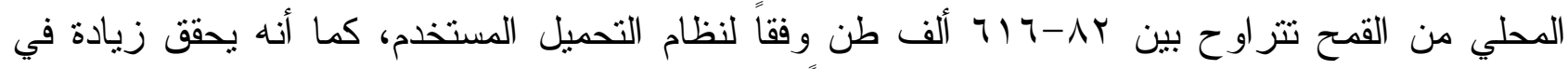

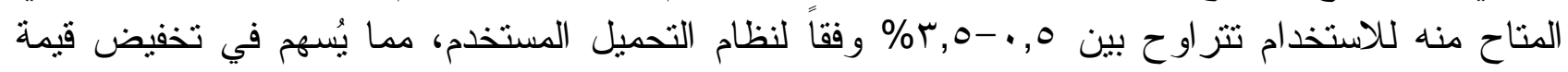

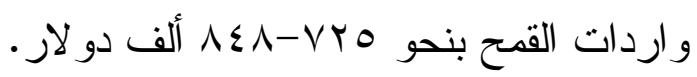


جدول (ء) الكفاءة الاقتصادية للقدان وللطن من القمح المُنتج باستخدام نظم تحميل محصول القمح بالأراضي القديمة وكفاءة استخدام موردي الأرض الزراعية ومياه الري لها.

\begin{tabular}{|c|c|c|c|c|c|c|c|c|c|c|c|c|c|c|}
\hline \multicolumn{2}{|c|}{ النظام الر ابع: } & \multirow[b]{2}{*}{ قصب السكر الخريفي } & \multicolumn{2}{|c|}{ النظام الثَالث: } & \multirow[b]{2}{*}{ |المنفرد } & \multicolumn{2}{|c|}{ النظام الثاني: الثاني } & \multirow[b]{2}{*}{ النبكر } & \multicolumn{2}{|c|}{ النظام الأول: } & \multirow[b]{2}{*}{ الشنتودية } & \multirow[b]{2}{*}{ المنفرد } & \multirow{2}{*}{\multicolumn{2}{|c|}{ 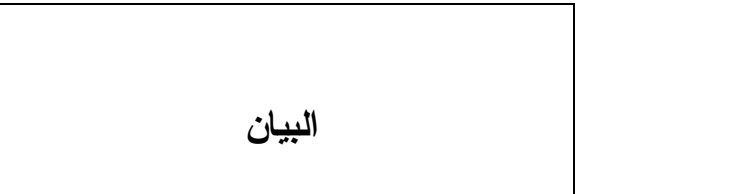 }} \\
\hline المحمل & القصب الخريلي على & & |القمح & التحميل & & المحمل & التحميل & & المحمل & التحميل مع الثتوي & & & & \\
\hline$\varepsilon r \cdot 1$ & TVYqs & $1 \mathrm{Tq94}$ & orq7 & 11094 & 7197 & $r T \leqslant Y$ & $9 \vee 9 \leqslant$ & $700 \mathrm{r}$ & $\varepsilon V T V$ & 1109. & T1Nor & OVTr & التكاليف الكلية (جنيه/فدان) & \\
\hline TVVA & ITYT & $1 . \leqslant 00$ & TVTV & $v \cdot 11$ & Erol & $\varepsilon 7 \varepsilon$ & 0109 & $\sum 790$ & TVYA & ATro & $00 \leqslant V$ & TNMT & التكاليف المتغيرة (جنيه/فذان) & \\
\hline $07 \leqslant \leqslant$ & $r \leqslant\{7)$ & IMAIV & $\Lambda \leq 77$ & 10TrE & 7141 & $\varepsilon V \cdot \Gamma$ & 14991 & 9490 & VOYO & $r \leqslant 0 \leqslant \Lambda$ & $T V \cdot T r$ & $9 \leqslant .0$ & الإير اد الكلي (جنيه/فدان) & 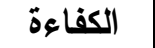 \\
\hline $1 \pi \leqslant T$ & VITA & ONYO & $r .79$ & $r V \Sigma 1$ & TVY & $1 \leq 71$ & $\varepsilon Y \cdot \varepsilon$ & $T V \varepsilon r$ & TVAA & rYq01 & r.IV. & r479 & صافى العائد (جنيه/فذان) & الاقتصادية \\
\hline TAT7 & 11 Trq & מזד & 0799 & NTIT & YTIV & हrrq & ^ᄉrq & $\leqslant 7 \ldots$ & $\varepsilon V \leqslant V$ & TTYKT & $Y) \leqslant V T$ & 0079 & العائد فوق التكاليف المتغيرة(جنيه/فان) & للقدان \\
\hline $1, \Gamma$ & $1, \S 1$ & $1, \leqslant 0$ & $1,0 \mathrm{~V}$ & T, rY & 1,11 & 1,50 & $1, \varepsilon \Gamma$ & $1, \varepsilon r$ & 1,09 & $r, 9 \Lambda$ & $r, q \varepsilon$ & $1,7 \varepsilon$ & العائد/التكاليف & \\
\hline$\cdot, \Gamma$ & $\cdot$, •, & $\cdot, \leqslant 0$ & $\cdot, 0 \mathrm{~V}$ & 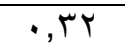 & $\cdot, 11$ & $\cdot, \leqslant 0$ & $\cdot, \varepsilon \Gamma$ & $\cdot, \varepsilon r$ & $\cdot, 09$ & 1,91 & r,, & $\cdot, 7 \varepsilon$ & أربحيةٌ الجنيه المُنفق (جنيه) & \\
\hline TOYs & rVqI & TTV & rIII & $\mu \mu^{\mu}$ & 1194 & TYAT & YOVA & r90 & $r \cdot 10$ & Y $\leqslant 77$ & rAl & T.Y. & التكاليف الكليةٌ (جنيه/طن) & \\
\hline $17 \pi$. & $1 \wedge \leqslant 0$ & Y10 & $\overline{1 \cdot \lambda r}$ & $19 . r$ & 119 & TrV & OrN & YI & TKY & 1041 & $r \cdot \Lambda$ & $1 \% 01$ & التكاليف المتغيرة (جنيه/طن) & \\
\hline 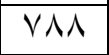 & $9 \cdot 1$ & Ir. & $T r \cdot 1$ & Irr. & 149 & 1.19 & $110 \mathrm{r}$ & ITr & TKY & $r r \leqslant 9$ & IIYY & Trar & صافي العائد (جنيه/طن) & \\
\hline $171 Y$ & $110 \xi$ & IVY & TYM. & TVTE & $0 . \varepsilon$ & r910 & rI9r & $r \cdot V$ & $r \cdot 19$ & TYMT & $119 \varepsilon$ & 1971 & العائد فوق التكاليف المتغيرة(جنيه/طن) & \\
\hline$\cdot, \mathrm{VT}$ & $\cdot, \cdots$ & $\varepsilon, \wedge$. & 1,11 & $\cdot, \cdots$ & $1, \varepsilon r$ & $\cdot, V \xi$ & $\cdot, \cdots$ & $\overline{l \cdot r} \cdot$ & $\cdot, 99$ & $\cdot, \cdots$ & $|r, r|$ & 1,11 & إنتاجيةٌ المتر المكبب (كجم/م ) & \\
\hline., $\mathrm{OV}$ & $\cdot, \mathrm{V}$ & $\cdot, \mathrm{OV}$ & $1, \pi$ & $1, r 9$ & $\cdot, 19$ & $\cdot, V 7$ & T, $\leqslant \varepsilon$ & $1, r V$ & $1, r_{1}$ & 19,70 & $\mid r, \Lambda 1$ & $1,0 Y$ & صافي عائد المتر المكب(جنيه/م) & 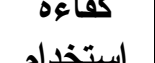 \\
\hline$\cdot$ & $\cdot$ & $\cdot$ & $\cdot$ & $19 \varepsilon$ & $\cdot$ & $\cdot$ & IV. & $\cdot$ & $\cdot$ & $r \varepsilon$ & · & $\cdot$ & الوفر في المياه المستخدمة (ألف م) & \\
\hline • & 1,7 & - & - & 1,9 . & - & - & 1,0 . & . & - & $1, \Lambda$. & - & - & مقياس كفاءة استغلال الأرض(() & \\
\hline$\cdot$ & 1,71 & . & . & $1,9 \leqslant$ & • & . & $1, \pi$ & . & . & $1, \wedge \varepsilon$ & $\cdot$ & $\cdot$ & مقياس كفاءة استغلل المياه(") & \\
\hline
\end{tabular}

(1) كفاءة استغلال الأرض= [إنتاجية القمح عند التحميل ؛ إنتاجيته منفرداً] + [إنتاجية المحصول الرئيسي عند التحميل ٪ إنتاجيته منفرداً].

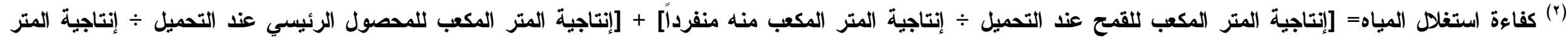




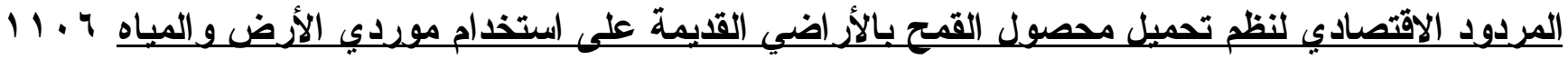

جدول (0) آثار استخدام نظم تحميل محصول القمح على أهم المتغيرات الاقتصادية للقمح.

\begin{tabular}{|c|c|c|c|c|c|c|}
\hline \multicolumn{2}{|c|}{ الزيادة في المتاح للاستخدام } & \multicolumn{2}{|c|}{ الخفض في قيمة الواردات } & \multicolumn{2}{|c|}{ الزيادة في الإنتاج المحلي } & \\
\hline$\%$ & ألف طن & $\%$ & ألف دولار & $\%$ & ألف طن & نظد تحميل القمح \\
\hline$\cdot, \leqslant \wedge$ & 10 & YO,VY & VYo & $1, \cdot 1$ & 10 & مع الطماطح الشتّوى \\
\hline$\cdot, \wedge$. & $T \varepsilon$. & $Y 7, I V$ & VTA & 1,19 & $1 \leqslant$. & على بنجر السكر \\
\hline$r, 01$ & 717 & $\Gamma \cdot, \cdot \Lambda$ & $\Lambda \leq \Lambda$ & $\mathrm{V}, \Lambda \mathrm{V}$ & 717 & على القطن \\
\hline$\cdot, \leqslant \mathrm{V}$ & NY & Y0,79 & VYO & $1, \cdot \varepsilon$ & $\Lambda T$ & على قُصب السكر الخريفي \\
\hline
\end{tabular}

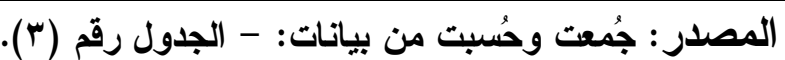

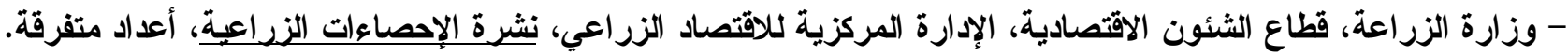

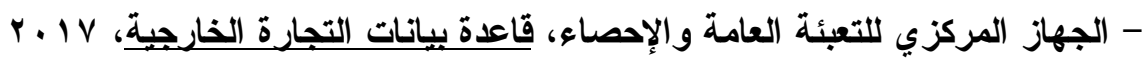

.(www.msrintranet.capmas.gov.eg)

- وزارة الزراعة واستصلاح الأراضي، قطاع الثئون الاقتصادية، الإدارة المركزية للاقتصاد الزراعي، نشرة الميزان الغذائي،

أعداد متفرقة.

الملخص و التوصيات

يُعد محصول القمح أحد أهم الحاصلات الزراعية التي تزتبط بالأمن الغذائي المصري، و على الرغم من أن الدولة تولي اهتماماً خاصاً بالنهوض بالإنتاج المحلي من القمح، إلا أن مصر ماز الت تواجه فجوة

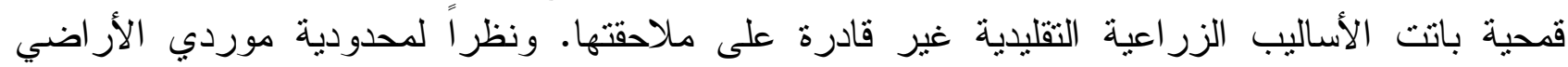
و المياه، فقد برزت أهمية التكثيف الزراعي كأحد الركائز غير التقليدية لزيادة الإنتاج المحلي منه ومن بينها التحميل الزر اعي، مما يستلزم إجر اء التقييم الاقتصادي لأثز نظم التحميل على إنتاج القمح بالأر اضي القديمة القية باعتبار أن نحو الري من المساحة المزروعة بالقمح في مصر تقع فيها، فضلاً عن أن بعض نظم تحميل القمح لا تصلح إلا في الأر اضي القديمة. ويستهدف البحث در اسة أثز استخدام هذه النظم على كل من: إنتاج

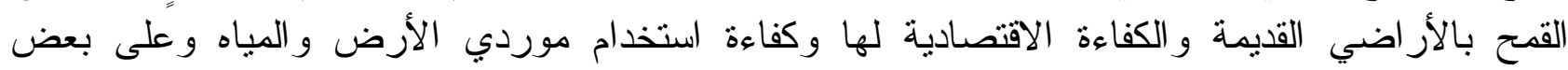
المتغير ات الاقتصادية ومقارنة ذلك بالقمح المنفرد. وتشمل هذه النظم تحميل القمح على كل من: الطماطم الثتوية وبنجر السكر و القطن وقصب السكر الخريفي.

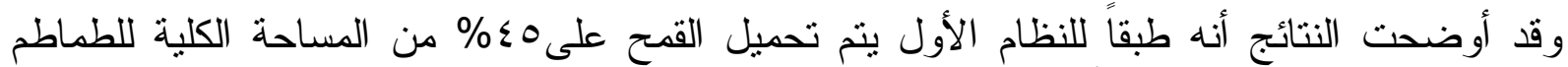
الثتوية أي على نحو Vr ألف فدان تُضيف نحو 1 ألف طن لإنتاج القهح المنفرد، في حين أنه يتم تحميل القمح على هץ\% من مساحة البنجر المنفرد أي على نحو 99 ألف فدان تضيف نحو ؛ ا, • مليون طن للقمح

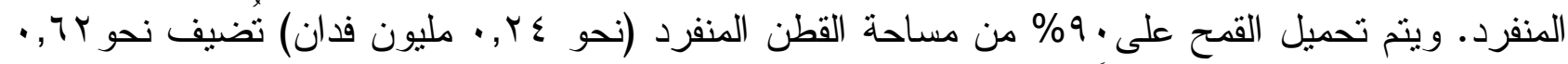

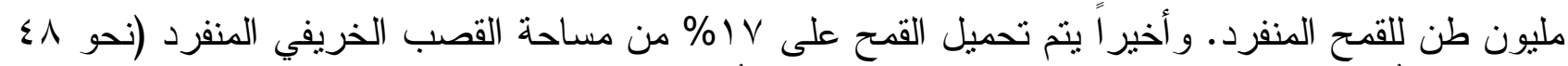
ألف فدان) تُضيف نحو مئن ألف طن للقمح المنفرد، كما تُضيف هذه النظم نحو تبن القمح إلى المو ارد العلفية اللازمة لتغذية الحيوانات. و أوضحت النتائج أن التكاليف الكلية و المتغيرة لإنتاج

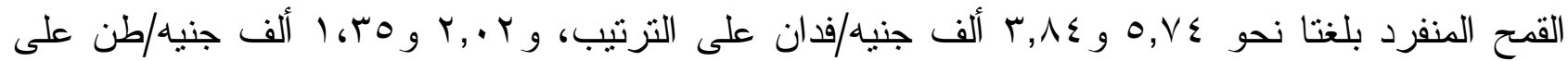

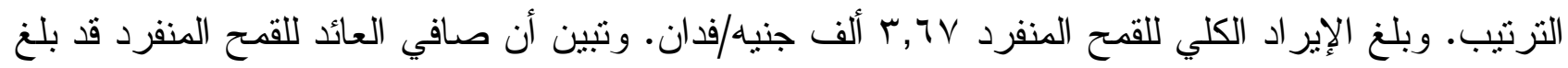
نحو V,T T ألف جنيه/فدان و 9 Y, ألف جنيه/طن. وبلغ العائد فوق التكاليف المتغيرة لفدان ولطن القمح المنفرد نحو 0,0V و 1,97 ألف جنيه على التزتيب، بينما بلغت نسبة العائد إلى التكاليف وأربحية الجنيه

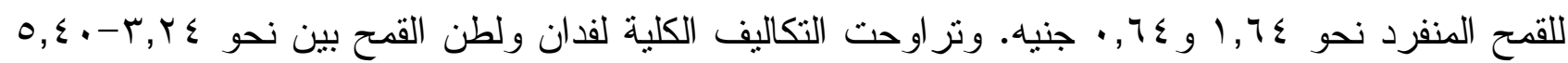

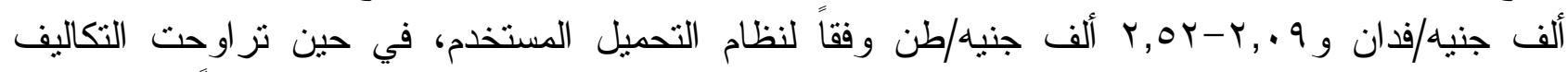

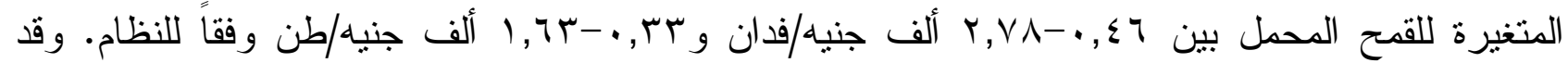

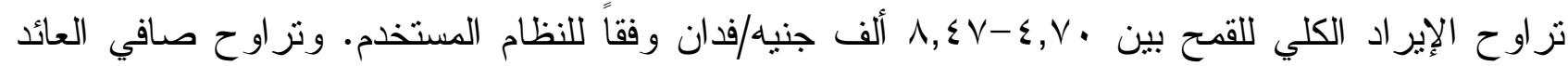




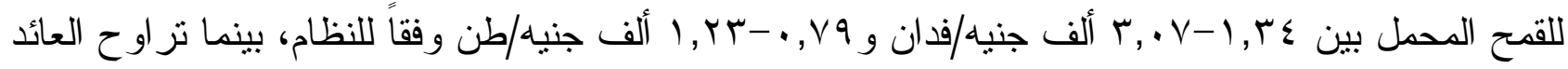

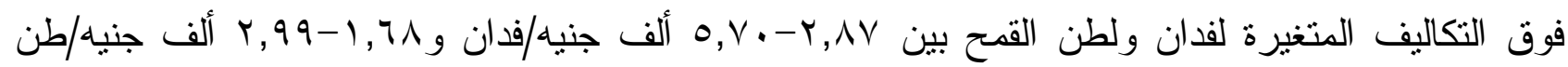

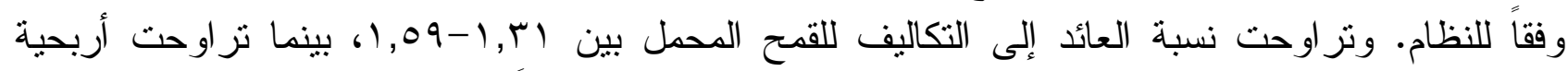

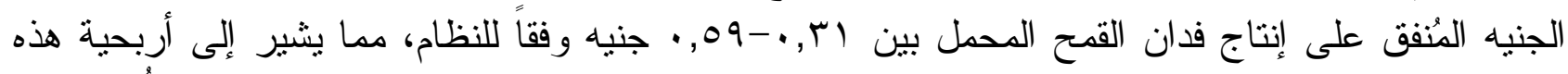
النظمٍ. ورغم أن هذه النظم تحقق إير ادات وعو ائد للقهح المحمل أقل منها للقمح المنفرد، إلا أنها تُعد بمثابة

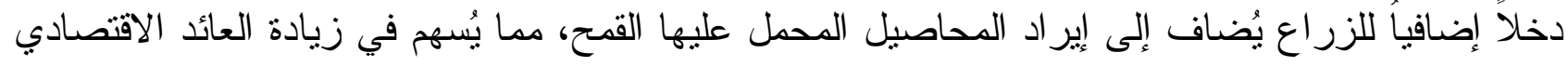

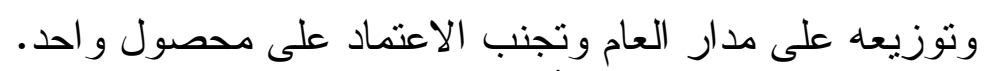
وتبين أن هذه النظم تُهه في تحقيق الكفاءة الإنتاجية و الاقتصادية لاستخدام موردي الأر اضي و المياه،

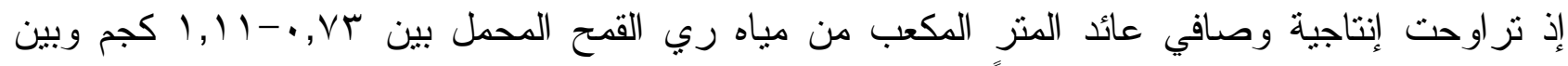

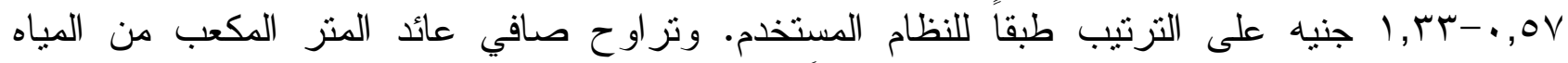

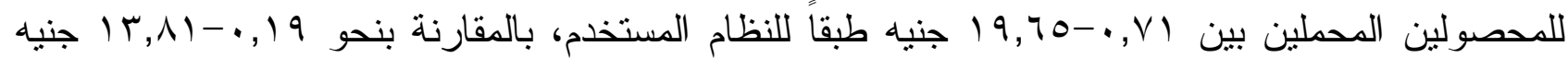
للمحاصيل الرئيسية المنفردة. وتبين أن تعميم استخدام هذه النظم يحقق زيادة في الإنتاج المحلي من القمح

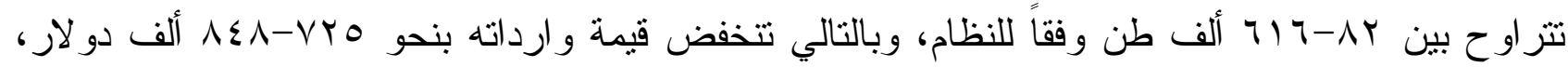

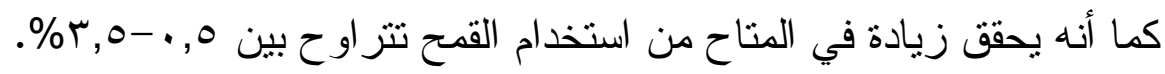
وفى ضوء هذه النتائج فإن الدر اسة توصي بنشر وتعميم زر اعة محصول القهم باستخدام نظم تحميله مع الطماطم الشتوي و على بنجر السكر وبالتتاوب على القطن و على قصب السكر الخريفي من خلال تعزيز التعاون بين معهد بحوث المحاصيل الحقلية بمركز البحوث الزر اعية وبين جهاز الإرشاد الزر اعي، وتدريب وليب

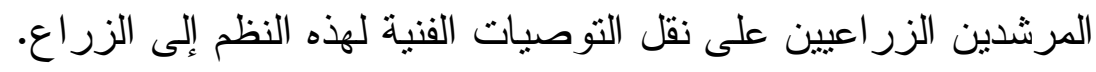

المر اجع

ا ـ الجهاز المركزي للتعبئة العامة و الإحصاء، نشرة المو ارد المائية و الري، أعداد مختلفة.

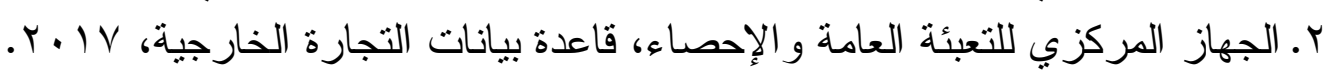

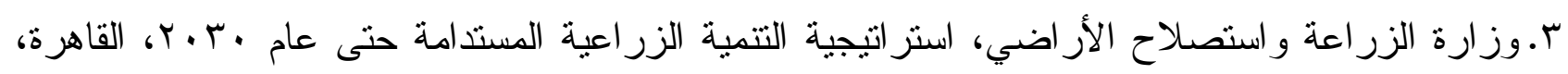
. . . 9

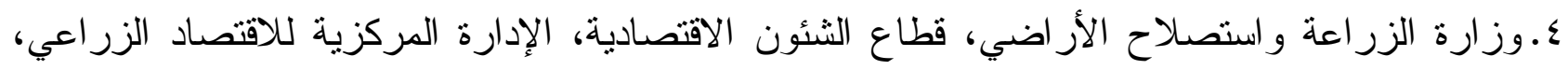
نشرة الإحصاءات الزر اعية، أعداد متفرقة.

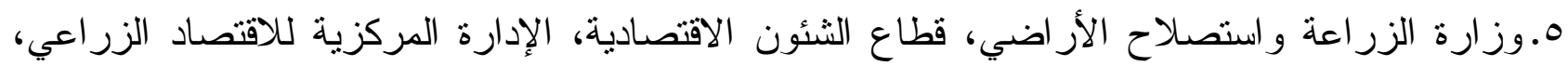
نشرة الميز ان الغذائي، أعداد متفرقة.

6. Abd El-Zaher, R., Shams, S., Mergheny, M., (2013). Effect of Intercropping Pattern and Nitrogen Fertilization on Intercropping Wheat with Tomato. Egypt. J. Appl. Sci. 28, 474-489.

7. Ouda, S.A.H., Zohry, A.E.-H., (2017). Crops Intensification to Reduce Wheat Gap in Egypt, in: Future of Food Gaps in Egypt: Obstacles and Opportunities. Springer International Publishing, Cham, pp. 37-56. doi:10.1007/978-3-319-46942-3_4

8. Ouda, S.A.H., Zohry, A.E.-H., 2016. Management of Climate Induced Drought and Water Scarcity in Egypt: Unconventional Solutions. doi:10.1007/978-3-31933660-2

9. Zohry, A.A., 2005. Effect of Relaying Cotton on some Crops under Bio-mineral N Fertilization Rates on Yield and Yield Components. Ann. Agric. Sci. 43, 89-103. 
المردود الاقتصادي لنظم تحميل محصول القمح بالأز اضي القدبمة على استخدام موردي الأرض والمباه 11 . 11

\section{The Economic Impact of Wheat Intercropping Systems in the Old Lands on the use of Land and Water Resources}

\section{Enas Moh. Abbas Saleh \\ Agricultural Economics Research Institute (AERI) - Agriculture Research Centre (ARC) Summary}

Wheat is the most important cereal crop in Egypt due to its importance in the Egyptian diet. However, the local wheat production does not cover the domestic consumption and consequently, boosting wheat local production is a national goal to narrow the gap between consumption and production and improve food security. On the other hand, the limited land and water resources available to Egypt precipitate the need to find ways to streamline these resources. These targets can be achieved by means of raising wheat productivity through growing high yielding varieties and using improved agro-techniques e.g. intercropping، where one crop share its life cycle or part of it with another crop. Thus, the current study attempts to assess the economic impact of wheat intercropping systems on wheat production in the old lands, since about $81 \%$ of wheat cultivated area is located at the old lands and some wheat intercropping systems are solely suitable for the old lands, as well. Consequently, the objectives of this study are mainly concerned with assessing the impact of using such systems on wheat production, economic efficiency, efficiency of using land and water resources and on some technical and economic variables as compared to wheat monoculture. These systems include wheat intercropping with winter tomato, sugar beet and autumn sugarcane and relay intercropping cotton with wheat. To accomplish these goals, the study depended on descriptive and statistical analysis techniques. The total and variable costs of sole wheat production reached about 5.74 and 3.84 thousand LE/feddan, respectively. The total revenue of sole wheat reached about 9.41 LE/feddan whereas, its $\mathrm{B} / \mathrm{C}$ ratio reached about 1.64. Moreover, the total and variable costs of intercropped wheat ranged between about 3.24-5.40 and 0.46-2.78 thousand LE/feddan, respectively based on wheat intercropping system used. Besides, the total revenue of intercropped wheat ranged between about 4.70-8.47 thousand LE/feddan upon the system used. Furthermore, the net return on wheat ranged between 1.34-3.07 LE/feddan while, their $\mathrm{B} / \mathrm{C}$ ratio of these system ranged between 1.31-1.59, indicating the profitability of these system. The results revealed that wheat intercropping systems contribute to improving the efficiency of using land and water resources since water productivity for intercropped wheat ranged between $0.73-1.11 \mathrm{~kg} / \mathrm{m}^{3}$ whereas, the economic return of one cubic meter for intercropped wheat ranged between $0.57-1.33 \mathrm{LE} / \mathrm{m}^{3}$ upon the system used. Based on these results, the study revealed that the dissemination of such systems on wheat produced in the old lands increases wheat production by about 82-616 thousand tons upon wheat intercropping system used. This in turn positively affected the deficit in the agricultural trade balance by reducing the value of wheat imports by about USD 725-848 thousand based on the system used. 